\title{
PENGARUH KINERJA LINGKUNGAN TERHADAP CORPORATE FINANCIAL PERFORMANCE DENGAN CORPORATE SOCIAL RESPONSIBILITY DISCLOSURE SEBAGAI VARIABEL INTERVENING
}

\author{
Riska Rusmaningsih ${ }^{1}$, Iwan Setiadi ${ }^{2}$ \\ Institut Teknologi dan Bisnis Ahmad Dahlan Jakarta, Indonesia ${ }^{1,2}$ \\ riskarusmaningsihr@gmail.com ${ }^{1}$
}

\begin{abstract}
This study aims to analyze the effect of environmental performance on Corporate Financial Performance (CSP) with Corporate Social Responsibility Disclosure (CSRD) as an intervening variable. With the number of research samples as many as 60 samples who were determined by the purposive sampling method. Tests were carried out using the path analysis test. The results of this study indicate that environmental performance affects CFP, environmental performance affects CSRD, CSRD affects CFP, and environmental performance affects CFP without going through the CSRD.
\end{abstract}

Keywords: Corporate Social Responsibility Disclosure, Corporate Financial Performance, Environmental Performance

\begin{abstract}
ABSTRAK
Penelitian ini bertujuan untuk menganalisis pengaruh kinerja lingkungan terhadap Corporate Financial Performance (CFP) dengan Corporate Social Responsibility Disclosure (CSRD) sebagai variabel intervening. Dengan jumlah sampel penelitian sebanyak 60 sampel yang ditentukan dengan metode purposive sampling. Pengujian dilakukan menggunakan uji path analysis. Hasil penelitian menunjukkan bahwa kinerja lingkungan berpengaruh terhadap CFP, kinerja lingkungan berpengaruh terhadap CSRD, CSRD berpengaruh terhadap CFP, dan kinerja lingkungan berpengaruh terhadap CFP tanpa melalui CSRD.
\end{abstract}

Kata Kunci: Corporate Social Responsibility Disclosure, Corporate Financial Performance, Kinerja Lingkungan 


\section{PENDAHULUAN}

Perusahaan dianggap sebagai lembaga yang dapat memberikan banyak keuntungan bagi masyarakat yang mana perusahaan harus memaksimalkan laba agar dapat memberikan sumbangan maksimal kepada masyarakat. Penilaian kemampuan perusahaan dalam menghasilkan laba yang maksimal ditandai dengan penilaian kinerja keuangan perusahaan. Menurut Hastawati dan Sarsiti (2016), laba tidak hanya sebagai ukuran suatu perusahaan dalam memenuhi kewajiban penyandang dana melainkan juga untuk menunjukkan prospek perusahaan di masa yang akan datang.

Seiring dengan berjalannya waktu, masyarakat kini mulai menyadari bahwa adanya dampak-dampak sosial yang diakibatkan oleh perusahaan dalam menjalankan aktivitas untuk mendapatkan laba yang maksimal. Dari adanya dampak tersebut, masyarakat berharap agar perusahaan dapat menangani dampakdampak sosial yang ditimbulkan atas aktivitas perusahaan terhadap kehidupan masyarakat yang sangat besar (Pujiasih, 2013). Sehingga pemerintah, para konsumen dan investor juga ikut memikirkan untuk kebijakan ekonomi makro mengenai pengelolaan lingkungan serta konversi alamnya. Karena adanya pencemaran lingkungan yang terjadi adalah dampak atas pengelolaan lingkungan oleh perusahaan yang tidak sesuai dengan standar pengelolaan lingkungan yang sudah ditetapkan.

Beberapa contoh perusahaan pertambangan yang mencemari lingkungan akibat aktivitas operasional perusahaan adalah PT. BDMS, PT. MA, PT. KPUC, dan PT. AMNK yang melakukan aktivitas pertambangan di Malinau, Kalimantan Utara. Perusahaan tambang ini sangatlah meresahkan dan merugikan masyarakat sekitar karena membuang limbah yang ada ke sungai Malinau dan dimana sungai tersebut menjadi sumber air dari masyarakat. Puncak konflik terjadi tanggal 4 Juli 2017 dimana tanggul dari PT. BDMS jebol dan mencemari sungai Malinau kemudian dilanjutkan dari tanggul PT. KPUC jebol yang berdampak pada distribusi air bersih masyarakat oleh PDAM di Malinau karena tidak mampu mengolah air yang sudah tercemar. Walaupun perusahaan sudah mencemari lingkungan dan merugikan masyarakat, perusahaan tetap menjalankan operasional 
perusahaan seperti biasa tanpa melakukan pertanggungjawaban akibat kerusakan yang telah dilakukan (www.kompasiana.com, 2017).

Program penilaian peringkat kinerja perusahaan dalam pengelolaan lingkungan hidup (PROPER) dibentuk oleh pemerintah melalui Kementerian Lingkungan Hidup dan Kehutanan yang telah dilaksanakan sejak tahun 2002. Kinerja lingkungan perusahaan diukur berdasarkan pemeringkatan berdasarkan tata cara dan kriteria sesuai dengan ketentuan Peraturan Menteri Lingkungan Hidup Nomor 3 Tahun 2014 tentang PROPER yaitu peringkat emas, hijau, biru, merah, dan hitam (SK-Menteri LHK 2019).

Dengan adanya PROPER yang diumumkan secara rutin, maka masyarakat diharapkan dapat mengetahui tingkat penataan pengelolaan lingkungan perusahaan dengan cara melihat peringkatnya berdasarkan warna. Menurut Permatasari (2013) yang dikutip oleh Safitri (2018), perusahaan dengan kinerja lingkungan yang baik tidak hanya mengungkapkan mengenai kepedulian perusahaan terhadap lingkungan. Perusahaan seharusnya mengungkapkan mengenai kualitas keamanan produk, tanggungjawab sosial perusahaan, hingga kepedulian perusahaan terhadap keselamatan dan kesejahteraan tenaga kerjanya. Kinerja lingkungan berdampak positif bagi masyarakat serta dapat meningkatkan reputasi perusahaan. Kinerja lingkungan juga akan meningkatkan kinerja keuangan perusahaan. Perusahaan dengan kinerja lingkungan yang baik dapat menarik perhatian para investor. Para investor tidak hanya melihat dari segi kinerja perusahaan secara keuangan tetapi juga dari segi kinerja lingkungan perusahaan.

Dalam perkembangan bisnis di Indonesia sekarang ini, dituntut untuk perusahaan agar dapat bersaing dan mempertahankan serta meningkatkan usahanya. Perusahaan tidak hanya berpusat pada internal perusahaan saja atau hanya mencari laba namun juga dapat meningkatkan hubungan sosial pada eksternal perusahaan yang akan menjadi tanggungjawab sosial perusahaan kepada para investor (Angela, 2015). Tanggungjawab ini dikenal sebagai Corporate Social Responsibility (CSR). 
Bahri dan Cahyani (2016) menyatakan pengungkapan kinerja lingkungan sebagai tanggungjawab sosial perusahaan dapat mempengaruhi kinerja keuangan perusahaan. Pandangan bahwa suatu perusahaan akan melakukan kinerja lingkungan yang baik akan melakukan pengungkapan yang tinggi diharapkan dapat menjadi bahan pertimbangan investor untuk tidak hanya melihat kinerja perusahaan dari segi finansial tetapi kinerja lingkungan juga perlu diperhatikan. Hal ini menunjukkan bahwa perusahaan yang menerapkan CSR mendapatkan perhatian positif dari para pelaku pasar.

Berdasarkan penelitian-penelitian yang dilakukan sebelumnya, masih didapatkan hubungan yang tidak berpengaruh positif yang menunjukkan hubungan antara kinerja lingkungan, kinerja keuangan, dan CSR belum konsisten. Sehingga peneliti tertarik untuk menguji kembali faktor-faktor yang pernah digunakan dalam penelitian sebelumnya dimana pada penelitian sebelumnya mayoritas dilakukan penelitian pada perusahaan manufaktur sehingga peneliti tertarik untuk melakukan penelitian pada perusahaan petambangan untuk menunjukkan apakah akan mendapatkan hasil yang konsisten atau tidak.

\section{TINJAUAN PUSTAKA DAN PENGEMBANGAN HIPOTESIS}

Menurut Widhiastuti dkk. (2017), kinerja lingkungan merupakan kinerja atas hubungan perusahaan dengan lingkungan. Dampak lingkungan harus dikelola dan dikendalikan untuk mengurangi dampak negatif pada lingkungan.

Corporate Financial Performance (CFP) menjadi salah satu faktor yang dilihat oleh calon investor untuk menentukan investasi saham sehingga perusahaan diharapkan dapat menjaga dan meningkatkan kinerja keuangan agar saham tersebut tetap eksis dan tetap diminatioleh investor (Santoso, 2017). Safitri (2018) menyimpulkan bahwa kinerja lingkungan berpengaruh terhadap CFP. Kinerja lingkungan perusahaan yang diungkapkan akan menjadi pemicu besar pada perusahaan dalam meningkatkan kinerja keuangan perusahaan. Berdasarkan hal tersebut, hipotesis yang diajukan adalah:

$\mathbf{H}_{1}$ : Kinerja lingkungan berpengaruh positif terhadap Corporate Financial Performance

Menurut Pujiasih (2013), CSR atau tanggung jawab sosial adalah kewajiban perusahaan untuk selalu menyeimbangkan antara kesejahteraan pemilik dan 
kesejahteraan lingkungan sosial, tidak hanya menyediakan barang dan jasa untuk masyarakat saja. Ada kaitan antara kinerja lingkungan dengan CSRD dimana perusahaan sudah banyak memikirkan mengenai dampak lingkungan yang disebabkan oleh aktivitas perusahaan kepada masyarakat di sekitar sehingga perusahaan menerapkan tanggungjawab sosial atas dasar peduli terhadap lingkungan. Angela (2015) menyimpulkan bahwa kinerja lingkungan memiliki pengaruh terhadap CSR. Perusahaan dengan tingkat PROPER yang baik menunjukkan kinerja lingkungan yang baik. Hipotesis kedua yang diajukan adalah:

$\mathbf{H}_{2}$ : Kinerja lingkungan berpengaruh positif terhadap Corporate Social Responsibility Disclosure

Lindawati dan Puspita (2015) menyatakan bahwa CSR dimaknai sebagai suatu bentuk komitmen perusahaan untuk meningkatkan kualitas hidup karyawan, komunitas lokal dan masyarakat secara lebih luas sebagai bentuk konstribusinya terhadap pembangunan ekonomi berkelanjutan yang tercermin melalui praktik bisnis yang baik. Sedangkan menurut Fahmi (2011) kinerja keuangan merupakan suatu gambaran tentang kondisi keuangan suatu perusahaan yang dianalisis dengan alat-alat analisis keuangan. Safitri (2018) menyatakan bahwa CSR berpengaruh positif terhadap CFP sehingga dapat dikatakan semakin tinggi CSR berarti akan semakin tinggi pula CFP.

H3: Corporate Social Responsibility Disclosure berpengaruh positif terhadap Corporate Financial Performance

Pujiasih (2013) menyatakan bahwa Corporate Social Responsibility (CSR) dapat mempengaruhi hubungan antara kinerja lingkungan dengan kinerja keuangan. Kondisi seperti ini terjadi karena dalam rangka menjaga keunggulan kompetitif maka perusahaan melakukan tanggungjawab sosial terhadap lingkungan. Menurut Widhiastuti (2017) CSR merupakan variabel intervening atas pengaruh peringkat PROPER pada ROA dan return saham. Pengaruh CSR secara langsung mendapat reaksi positif dari stakeholders, dengan melakukan CSR secara kontinu, stakeholders akan menilai bahwa perusahaan tersebut memiliki kinerja keuangan yang lebih baik.

H4: Corporate Social Responsibility Disclosure dapat memediasi antara kinerja lingkungan terhadap Corporate Financial Performance 


\section{METODE PENELITIAN}

Penelitian ini menggunakan desain penelitian kuantitatif dengan pendekatan penelitian analisis asosiatif. Penelitian ini menyajikan gambaran mengenai hubungan antara variabel yang diteliti. Populasi yang digunakan dalam penelitian ini adalah perusahaan pertambangan yang terdaftar di Bursa Efek Indonesia periode 2015-2019. Penelitian ini menggunakan teknik purposive sampling. Total data amatan dalam penelitian ini adalah 60 sampel.

\section{Definisi Operasional dan Pengukuran Variabel}

\section{Kinerja Lingkungan}

Kinerja lingkungan adalah kinerja yang terkait dengan hubungan perusahaan dengan lingkungan mengenai dampak lingkungan dari sumber daya yang digunakan (Widhiastuti, 2017). Menurut Rakhiemah dalam Pujiasih (2013), kinerja lingkungan diukur melalui prestasi perusahaan dalam mengikuti PROPER. Program yang merupakan salah satu upaya yang dilakukan Kementrian Lingkungan Hidup (KLH) untuk mendorong penataan perusahaan dalam pengelolaan lingkungan hidup melalui instrument informasi. Cara pengukuran menggunakan cara dummy: jika diungkapkan $=$ skor 2 dan tidak diungkapkan $=$ skor 1.

\section{Corporate Financial Performance}

Menurut Sucipto dalam Pujiasih (2013), kinerja keuangan merupakan penentuan ukuran-ukuran tertentu yang dapat mengukur keberhasilan suatu perusahaan dalam menghasilkan laba. Dalam penelitian ini, CFP diukur menggunakan rumus rasio keuangan yaitu:

$$
\text { Tobins' } Q=\frac{M V E+D E B T}{\text { Total aset }}
$$




\section{Corporate Social Responsibility Disclosure}

CSRD adalah kewajiban perusahaan untuk selalu menyeimbangkan antara kesejahteraan pemilik dan kesejahteraan lingkungan sosial (Pujiasih, 2013). Dalam penelitian ini, CSRD diukur menggunakan index CSR. Pendekatan CSRD dalam penelitian ini menggunakan variabel dummy yaitu jika perusahaan mengungkapkan diberi nilai 1 dan jika perusahaan tidak mengungkapkan diberi nilai 0. Selanjutnya indeks CSR dihitung menggunakan rumus:

$$
C S R=\frac{V}{M}
$$

CSR merupakan indeks pengungkapan CSR, V adalah jumlah item yang diungkapkan perusahaan dan $\mathrm{M}$ adalah jumlah item yang seharusnya diungkapkan.

\section{HASIL PENGUJIAN HIPOTESIS}

\section{Deskripsi Data}

Analisis deskriptif data yang diambil untuk penelitian ini adalah untuk memperoleh gambaran umum terhadap data yang digunakan dalam penelitian ini dapat dilihat pada tabel berikut ini:

\section{Descriptive Statistics}

\begin{tabular}{l|r|r|r|r|r} 
& N & Minimum & Maximum & Mean & Std. Deviation \\
\hline $\begin{array}{l}\text { Corporate Financial } \\
\text { Performance }\end{array}$ & 60 & 17 & 237 & 78.12 & 46.361 \\
\hline $\begin{array}{l}\text { Corporate Social } \\
\text { Responsibility Disclosure }\end{array}$ & 60 & 3 & 64 & 36.73 & 16.794 \\
\hline Valid N (listwise) & 60 & & & & \\
\hline
\end{tabular}

Sumber: SPSS Versi 25 (Data diolah, 2020)

\section{Uji Asumsi Klasik}

\section{Uji Normalitas}

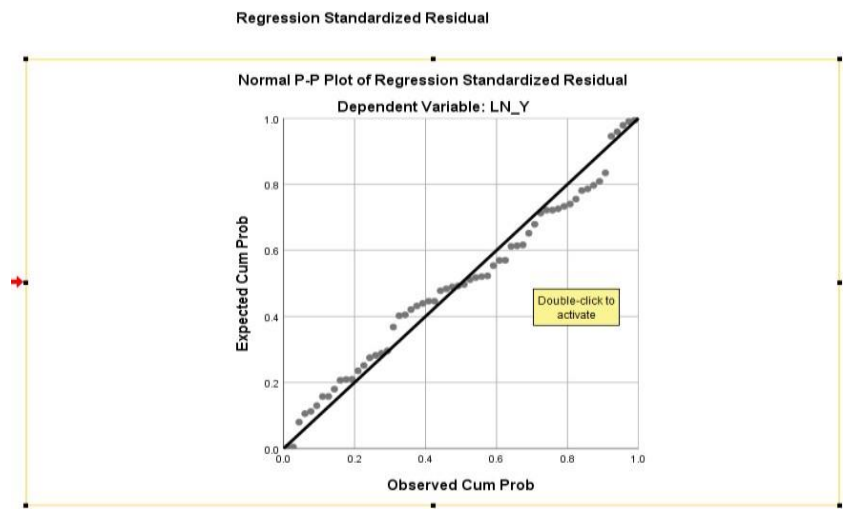

Sumber: SPSS Versi 25 (Data diolah, 2020) 
Dari hasil uji normalitas pada gambar 4.1 dengan menggunakan analisis grafik yaitu menggunakan grafik normal probability plot menunjukkan bahwa grafik memberikan pola distribusi normal dan terlihat titik-titik menyebar di sekitar garis diagonal serta penyebarannya ada disekitar garis diagonal. Untuk lebih memastikan apakah data residual terdistribusi secara normal atau tidak, maka dilakukan pengujian one sample kolmogorov smirnov.

\begin{tabular}{|c|c|c|}
\hline One-Sample Kol & ogorov-Smir & $\begin{array}{l}\text { Iov Test } \\
\text { Unstandardiz } \\
\text { ed Residual }\end{array}$ \\
\hline \multicolumn{2}{|l|}{$N$} & 60 \\
\hline \multirow[t]{2}{*}{ Normal Parameters ${ }^{a, b}$} & Mean & .0000000 \\
\hline & Std. Deviation & .51363402 \\
\hline \multirow[t]{3}{*}{ Most Extreme Differences } & Absolute & .087 \\
\hline & Positive & .087 \\
\hline & Negative & -.084 \\
\hline \multicolumn{2}{|l|}{ Test Statistic } & .087 \\
\hline \multicolumn{2}{|l|}{ Asymp. Sig. (2-tailed) } & $.200^{\mathrm{c}, \mathrm{d}}$ \\
\hline \multicolumn{3}{|c|}{ a. Test distribution is Normal. } \\
\hline \multicolumn{3}{|l|}{ b. Calculated from data. } \\
\hline \multicolumn{3}{|c|}{ c. Lilliefors Significance Correction. } \\
\hline \multicolumn{3}{|c|}{ d. This is a lower bound of the true significance. } \\
\hline
\end{tabular}

Sumber: SPSS Versi 25 (Data diolah, 2020)

Hasil pengujian uji normalitas dengan uji Kolmogorof-Smirnov memperlihatkan besarnya signifikan diatas 0,05 atau $5 \%$ yaitu 0.200 . Dengan demikian dapat disimpulkan bahwa nilai seluruh variabel memiliki distribusi normal dan model regresi dapat dipakai untuk pengujian selanjutnya.

\section{Uji Multikolonieritas}

\begin{tabular}{|c|c|c|c|c|c|c|c|c|}
\hline \multicolumn{9}{|c|}{ Coefficients $^{a}$} \\
\hline & & \multicolumn{2}{|c|}{ Unstandardized Coefficients } & \multirow{2}{*}{$\begin{array}{c}\text { Standardized } \\
\text { Coefficients } \\
\text { Beta }\end{array}$} & \multirow[b]{2}{*}{$t$} & \multirow[b]{2}{*}{ Sig. } & \multicolumn{2}{|c|}{ Collinearity Statistics } \\
\hline \multicolumn{2}{|c|}{ Model } & B & Std. Error & & & & Tolerance & VIF \\
\hline \multirow[t]{3}{*}{1} & (Constant) & 5.398 & .390 & & 13.827 & .000 & & \\
\hline & $L N \_X$ & .699 & .229 & .426 & 3.057 & .003 & .725 & 1.379 \\
\hline & LN_Z & .418 & .122 & -.478 & -3.430 & .001 & .725 & 1.379 \\
\hline
\end{tabular}

Sumber: SPSS Versi 25 (Data diolah, 2020)

Berdasarkan tabel diatas dapat diketahui bahwa model tidak terdapat multikolonieritas masalah, karena VIF (variabel inflation factor) tidak lebih dari 
10 yaitu nilai VIF kinerja lingkungan adalah 1,379 dan nilai VIF Corporate Social Responsibility Disclosure adalah 1,379. Demikian juga nilai tolerance pada masing-masing variabel, nilai tolerance lebih besar dari 0,10 yaitu nilai tolerance kinerja lingkungan sebesar 0,725 dan nilai tolerance Corporate Social Responsibility Disclosure sebesar 0,725 sehingga dapat disimpulkan bahwa tidak terjadi gejala multikolonieritas antar variabel dan model regresi dalam penelitian ini layak digunakan.

\section{Uji Autokorelasi}

\begin{tabular}{|l|l|l|l|l|l|}
\hline \multicolumn{7}{|c|}{ Model Summary $^{\mathbf{b}}$} \\
Model & $\mathrm{R}$ & R Square & $\begin{array}{c}\text { Adjusted } \mathrm{R} \\
\text { Square }\end{array}$ & $\begin{array}{c}\text { Std. Error of } \\
\text { the Estimate }\end{array}$ & $\begin{array}{c}\text { Durbin- } \\
\text { Watson }\end{array}$ \\
\hline 1 & $.443^{\text {a }}$ & .197 & .168 & .52257 & 1.584 \\
\hline \multicolumn{3}{|c|}{$\begin{array}{l}\text { a. Predictors: (Constant), CSRD, KinerjaLingkungan } \\
\text { b. Dependent Variable: CFP }\end{array}$} \\
\hline
\end{tabular}

Sumber: SPSS Versi 25 (Data diolah, 2020)

Dari hasil regresi model summary menunjukan bahwa dalam penelitian ini tidak terdapat autokorelasi karena Menurut Sunyoto (2016:98) dalam pengambilan keputusan ada tidaknya autokorelasi dengan menggunakan DurbinWatson Test ( $D$-W Test) yaitu bila nilai D-W terletak diantara -2 sampai +2 berarti di indikasi tidak ada autokorelasi. Nilai Durbin Watson dalam penelitian ini adalah sebesar 1,584 dimana nilai tersebut terletak diantara -2 sampai dengan +2 . Oleh karena itu, dapat disimpulkan bahwa tidak terdapat autokorelasi dalam penelitian ini dan model regresi dalam penelitian ini layak digunakan.

\section{Uji Heteroskedastisitas}

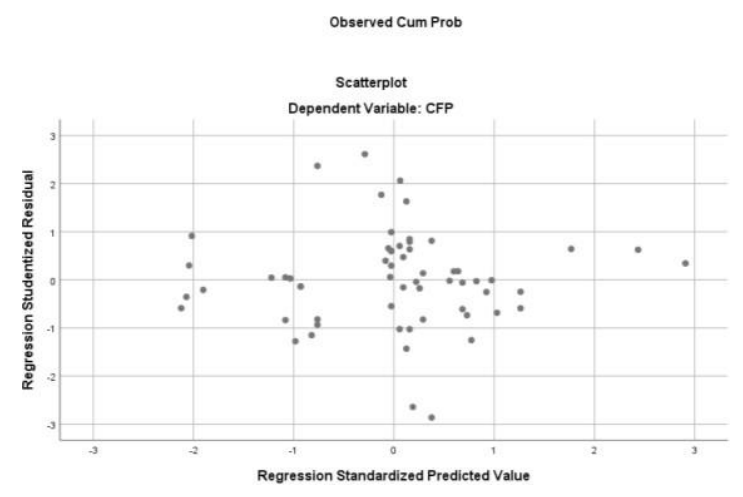

Sumber: SPSS Versi 25 (Data diolah, 2020) 
Berdasarkan hasil uji heteroskedastisitas pada gambar, menunjukan bahwa ada pola yang jelas, dimana titik-titik menyebar diatas dan dibawah angka 0 pada sumbu Y, maka dapat disimpulkan bahwa tidak terjadi heteroskedastisitas pada model regresi yang digunakan dalam penelitian ini.

\section{Analisis Regresi}

Koefisien regresi dalam model persamaan I adalah:

\begin{tabular}{|c|c|c|c|c|c|c|}
\hline \multicolumn{7}{|c|}{ Coefficients $^{a}$} \\
\hline \multirow[b]{2}{*}{ Model } & & \multicolumn{2}{|c|}{ Unstandardized Coefficients } & \multirow{2}{*}{$\begin{array}{c}\text { Standardized } \\
\text { Coefficients } \\
\text { Beta }\end{array}$} & \multirow[b]{2}{*}{$t$} & \multirow[b]{2}{*}{ Sig. } \\
\hline & & B & Std. Error & & & \\
\hline \multirow[t]{2}{*}{1} & (Constant) & 3.106 & .103 & & 30.218 & .000 \\
\hline & KinerjaLingkungan & .983 & .210 & .524 & 4.687 & .000 \\
\hline
\end{tabular}

Sumber: SPSS Versi 25 (Data diolah, 2020)

Model Summary

\begin{tabular}{ll|r|r|r} 
Model & R & R Square & $\begin{array}{c}\text { Adjusted R } \\
\text { Square }\end{array}$ & $\begin{array}{c}\text { Std. Error of } \\
\text { the Estimate }\end{array}$ \\
\hline 1 & $.524^{\mathrm{a}}$ & .275 & .262 & .56304 \\
\hline \multicolumn{2}{r}{ a. Predictors: (Constant), KinerjaLingkungan }
\end{tabular}

Sumber: SPSS Versi 25 (Data diolah, 2020)

Dari tabel di atas terlihat nilai koefisien regresinya adalah 0.524. Sedangkan dari tabel Model Summary di atas, nilai Adjusted $R$ Square adalah 0.262. Nilai ini dapat digunakan untuk menentukan nilai koefisien jalur denganresidualnya, yakni $\mathrm{P} \beta 1=\sqrt{ }(1$ $\left.R^{2} 1\right)=\sqrt{ }(1-0,262)=0,8591$.

Koefisien regresi dalam model persamaan II

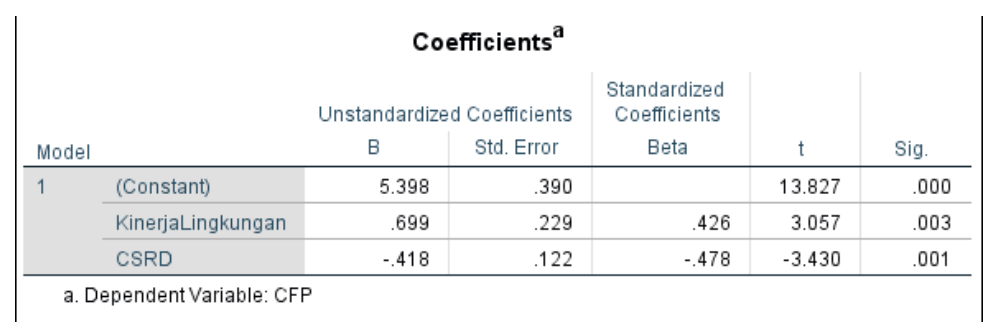

Sumber: SPSS Versi 25 (Data diolah, 2020)

Dari tabel koefisien diatas terlihat nilai-nilai koefisien regresinya adalah:

1. Koefisien kinerja lingkungan adalah $\mathrm{P} 2=0,426$

2. Koefisien Corporate Social Responsibility Disclosure adalah $\mathrm{P} 3=-0,478$ 


\section{Model Summary}

\begin{tabular}{ll|r|r|r} 
Model & R & R Square & \multicolumn{1}{c}{$\begin{array}{c}\text { Adjusted R } \\
\text { Square }\end{array}$} & \multicolumn{1}{c}{$\begin{array}{c}\text { Std. Error of } \\
\text { the Estimate }\end{array}$} \\
\hline 1 & $.443^{\text {a }}$ & .197 & .168 & .52257 \\
\hline
\end{tabular}

a. Predictors: (Constant), CSRD, KinerjaLingkungan

Sumber: SPSS Versi 25 (Data diolah, 2020)

Sedangkan dari tabel Model Summary di atas, nilai Adjusted $R$ Square adalah 0,168. Nilai ini dapat digunakan untuk menemukan nilai koefisien jalur dengan residualnya, yakni $\mathrm{P} \beta 2=\sqrt{ }(1-0,168)=0,9121$.

$$
\begin{array}{r}
\text { Regresi } \mathrm{I}=\mathrm{Y} 2=3.106+0.983 \mathrm{X} 1+\mathrm{e} \\
\text { Regresi II }=\mathrm{Y} 1=5.398+0,699 \mathrm{X} 1-0.418 \mathrm{X}+\mathrm{e}
\end{array}
$$

Analisis Jalur

$\mathrm{P}_{2}: 0,426$

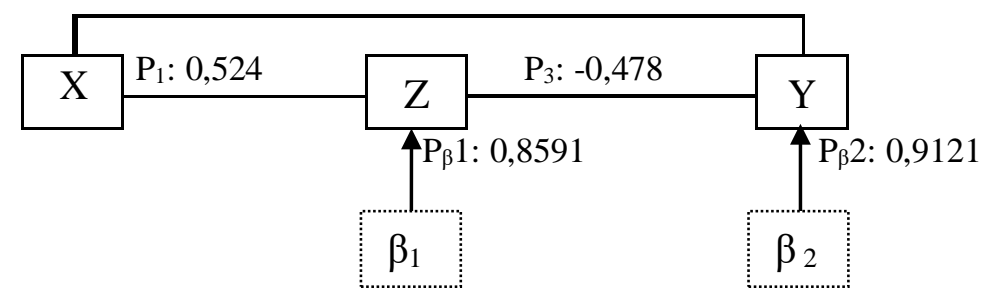

Koefisien pengaruh langsung, tidak langsung dan total:

1. Pengaruh langsung kinerja lingkungan terhadap Corporate Financial Performance dilihat dari nilai koefisien regresi kinerja lingkungan terhadap Corporate Financial Performance yakni P2 sebesar 0,426.

2. Pengaruh tidak langsung kinerja lingkungan terhadap Corporate Financial Performance melalui Corporate Social Responsibility Disclosure dilihat dari perkalian antara nilai koefisien regresi kinerja lingkungan terhadap Corporate Social Responsibility Disclosure dengan nilai koefisien regresi Corporate Social Responsibility Disclosure tehadap Corporate Financial Performance yakni P1 x P3 = 0,524 x $(-0,478)=-0,2505$.

3. Pengaruh total kinerja lingkungan tehadap Corporate Financial Performance dilihat dari nilai pengaruh langsung + pengaruh tidak langsung $=0,426+(-$ $0,2505)=0,1755$. 


\section{Uji Hipotesis}

\section{Uji F}

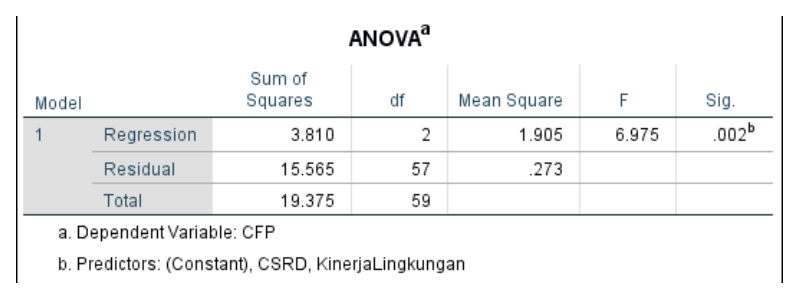

Sumber: SPSS Versi 25 (Data diolah, 2020)

Hasil pengolahan data yang terlihat pada tabel di atas bahwa nilai Fhitung sebesar 6,975 dengan nilai probabilitas sebesar 0,002. Berdasarkan tabel tersebut, hasil nilai signifikansi lebih kecil dari nilai probabilitas $0,05(\alpha=5 \%)$ atau nilai $0,002<0,05$. Jadi dapat disimpulkan bahwa kinerja lingkungan dan CSRD bepengaruh secara simultan terhadap CFP.

\section{Uji t}

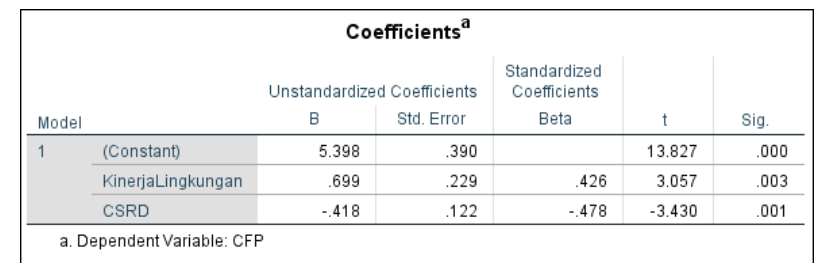

Sumber: SPSS Versi 25 (Data diolah, 2020)

Berdasarkan tabel di atas menunjukkan bahwa kinerja lingkungan memiliki nilai signifikansi sebesar 0,003. Nilai signifikansi tersebut lebih kecil dari nilai probabilitas $0,05(\alpha=5 \%)$ atau nilai $0,003<0,05$. Variabel kinerja lingkungan mempunyai nilai t hitung sebesar 3,057 dengan t tabel sebesar 1,98027. Jadi t hitung > t tabel maka dapat disimpulkan bahwa kinerja lingkungan memiliki kontribusi terhadap CFP. Nilai t positif menunjukkan bahwa variabel kinerja lingkungan mempunyai hubungan yang searah dengan CFP. Jadi dapat disimpulkan bahwa kinerja lingkungan berpengaruh secara parsial terhadap CFP.

Berdasarkan tabel di atas menunjukkan bahwa CSRD memiliki nilai signifikansi sebesar 0,001. Nilai signifikansi tersebut lebih kecil dari nilai probabilitas $0,05(\alpha=5 \%)$ atau nilai $0,001<0,05$. Jadi dapat disimpulkan bahwa CSRD dapat berpengaruh secara parsial terhadap pengungkapan CFP. 


\section{Uji Koefisien Determinasi}

\begin{tabular}{l|l|r|r|r}
\hline & \multicolumn{3}{c}{ Model Summary } \\
Model & R & R Square & $\begin{array}{c}\text { Adjusted R } \\
\text { Square }\end{array}$ & $\begin{array}{c}\text { Std. Error of } \\
\text { the Estimate }\end{array}$ \\
\hline 1 & $.443^{\text {a }}$ & .197 & .168 & .52257 \\
\hline
\end{tabular}

a. Predictors: (Constant), CSRD, KinerjaLingkungan

b. Dependent Variable: CFP

Sumber: SPSS Versi 25 (Data diolah, 2020)

Berdasarkan tabel di atas dapat diketahui bahwa nilai $R$ Square sebesar 0,197. Hal ini berarti bahwa 19,7\% Corporate Financial Performance dapat dijelaskan oleh variasi variabel independen yaitu kinerja lingkungan dan Corporate Social Responsibility Disclosure, sisanya sebesar 80,3\% dijelaskan oleh sebab-sebab lain di luar variabel penelitian yang tidak diteliti dalam penelitian ini. Nilai $\mathrm{R}=0,443$ menunjukkan bahwa koefisien korelasi sebesar 44,3\%. Dari nilai ini dapat disimpulkan bahwa hubungan antara kinerja lingkungan, Corporate Social Responsibility Disclosure terhadap Corporate Financial Performance memiliki posisi yang kurang kuat karena berada di bawah $50 \%$.

\section{Uji Sobel}

Nilai Sab dari Sobel test tidak dapat dihasilkan langsung dari hasil regresi tetapi dengan perhitungan secara manual dengan rumus sobel test.

$$
\mathbf{s a b}=\sqrt{b^{2} s a^{2}+a^{2} s b^{2}+s a^{2} s b^{2}}
$$

Hasil perhitungan nilai Sab dari sobel test adalah sebesar 0,151. Kemudian dilakukan perhitungan $\mathrm{t}$ statistik untuk mengetahu pengaruh intervening dengan rumus:

$$
\mathbf{t}=\frac{a b}{S a b}
$$

Hasil perhitungan dari t statistik adalah -2,721 dengan nilai t tabel sebesar 2,002. Sehingga $t$ hitung $<\mathrm{t}$ tabel menunjukkan bahwa H0 diterima artinya bahwa CSRD tidak mampu memediasi hubungan pengaruh kinerja lingkungan terhadap CFP atau pengaruh kinerja lingkungan terhadap CFP tidak melalui CSRD. 


\section{KESIMPULAN, KETERBATASAN DAN SARAN}

Berdasarkan hasil penelitian dan pembahasan yang telah dikemukakan maka dapat diambil kesimpulan dari penelitian ini yaitu kinerja lingkungan berpengaruh signifikan terhadap CFP, kinerja lingkungan berpengaruh signifikan terhadap CSRD, CSRD berpengaruh signifikan terhadap CFP, dan CSRD tidak mampu menjadi variabel intervening antara pengaruh kinerja lingkungan terhadap CFP. Keterbatasan dalam penelitian ini adalah penelitian ini hanya meneliti satu variabel independen yaitu kinerja lingkungan, masih terdapat unsur subjektivitas dalam menilai indeks pengungkapan tanggungjawab sosial perusahaan, dan sampel yang digunakan terbatas karena tidak semua perusahaan konsisten dan mengikuti PROPER sehingga kurang mencerminkan kondisi jangka panjang perusahaan. Saran yang dapat diberikan dari adanya penelitian ini yaitu perusahaan seharusnya lebih memperhatikan mengenai kondisi lingkungan, kesehatan dan keselamatan kerja karyawan, memberikan kontribusi kepada karyawan dan masyarakat sekitar, mengurangi dampak yang ditimbulkan atas operasional perusahaan, dan perusahaan mengikuti PROPER secara rutin agar dapat meningkatkan citra perusahaan dan kinerja keuangan perusahaan.

\section{REFERENCES}

Angela. 2015. Pengaruh Kinerja Lingkungan terhadap Kinerja Finansial dengan Pengungkapan Corporate Social Responsibility (CSR) sebagai Variabel Intervening. Skripsi Fakultas Ekonomi Universitas Sanata Dharma Yogyakarta.

Asiah, Nur. 2014. Pengaruh Kinerja Keuangan dan Kinerja Lingkungan terhadap Pengungkapan Corporate Social Responsibility pada Perusahaan Manufaktur di Bursa Efek Indonesia. Skripsi Fakultas Ekonomi dan Bisnis Islam Universitas Islam Negeri (UIN) Alauddin Makassar.

Bahri, Syaiful, dan Febby Anggista Cahyani. 2016. Pengaruh Kinerja Lingkungan terhadap Corporate Financial Performance dengan Corporate Social Responsibility Disclosure sebagai Variabel Intervening. Jurnal Ekonomi Universitas Kediri.

Dewi, Syahrina N. 2019. Pengaruh Kinerja Lingkungan terhadap Kinerja Keuangan dengan Corporate Social Responsibility sebagai Variabel Intervening. Jurnal Ekonomi Manajemen Sumber Daya Vol. 21 No. 2 Universitas Pattimura.

Fahmi, Irham. 2011. Analisis Laporan Keuangan. Lampulo: ALFABETA. Ghozali, Imam. 2006. Aplikasi Analisis Multivariate dengan Program SPSS,

Cetakan IV. Semarang: Badan Penerbit Universitas Diponegoro. 
Ghozali, Imam. 2011. Aplikasi Analisis Multivariate dengan Program IBM SPSS 19. Semarang: Badan Penerbit Universitas Diponegoro, Semarang. Hastawati, R. Rahayu, dan Sarsiti. 2016. Pengaruh Kinerja Lingkungan dan

Corporate Social Responsibility (CSR) terhadap Kinerja Keuangan pada Perusahaan Manufaktur yang Terdaftar di Bursa Efek Indonesia Tahun 20112013. Jurnal Penelitian dan Kajian Ilmiah Fakultas Ekonomi Universitas Surakarta.

Juliandi, Azuar. 2014. Metodologi Penelitian Bisnis Konsep dan Aplikasi. Umsu Press: Medan.

Karina, Desita Riyanta Mitra. 2020. Pengaruh Corporate Social Responsibility terhadap Nilai Perusahaan dengan Good Corporate Governance sebagai Pemoderasi. Jurnal Akuntansi Institut Teknologi dan Bisnis Ahmad Dahlan Jakarta.

Mandaika, Yusi., Hasan Salim. 2013. Pengaruh Ukuran Perusahaan, Kinerja Keuangan, Tipe Industri, dan Financial Leverage Terhadap Pengungkapan CSR. Jurnal Akuntansi/ 8(2): 181-201.

Moeljadi, 2014. Factors Effecting Firm Value: Theoritical Study on Manufacturing Firms in Indonesia. South East Asia Journal of Contemporary Business, Economics and Law.

Notoatmodjo, Soekidjo. 2010. Metodologi Penelitian Kesehatan. Jakarta: Rineka Cipta.

Nur, M., D. Priantinah. 2012. Analisis Faktor-Faktor yang Mempengaruhi Pengungkapan CSR di Indonesia (Studi Empiris pada Perusahaan Berkategori High Profile yang Listing di Bursa Efek Indonesia. Jurnal Nominal/ 1(1).

Pujiasih. 2013. Pengaruh Kinerja Lingkungan terhadap Kinerja Keuangan dengan Corporate Social Responsibility (CSR) sebagai Variabel Intervening. Skripsi Fakultas Ekonomi Universitas Negeri Semarang.

Putra, Yudi Partama. 2017. Pengaruh Kinerja Lingkungan terhadap Kinerja Keuangan dengan Pengungkapan Corporate Social Responsibility (CSR) sebagai Variabel Intervening. Jurnal Akuntansi Vol 2 No.2 Universitas Muhammadiyah Bengkulu.

Rakhiemah, Aldilla Noor, dan Dian Agustia. 2009. Pengaruh Kinerja Lingkingan terhadap Corporate Social Responsibility (CSR) Disclosure dan Kinerja Finansial Perusahaan Manufaktur yang Terdaftar di Bursa Efek Indonesia. Simposium Nasional Akuntansi XII Universitas Airlangga.

Rakhmawati, Ala. 2012. Pengaruh Kinerja Lingkungan Terhadap Kinerja Keuangan dengan CSR sebagai Variabel Intervening. Skripsi S1 Fakultas Ekonomi Universitas Diponegoro.

Republik Indonesia, Keputusan Menteri Lingkungan Hidup dan Kehutanan Nomor SK.1409/MENLHK/SETJEN/PKL.4/12/2019 tentang Hasil Penilaian Peringkat Kinerja Perusahaan dalam Pengelolaan Lingkungan Hidup Tahun 2018-2019.

Robbins. Coutler. 1999. Manajemen Edisi ke-enam. Jakarta: PT. Prenhallindo. Safitri, Dian Ayu. 2018. Pengaruh Kinerja Lingkungan terhadap Corporate Financial Performance dengan Corporate Social Responsibility Disclosure sebagai Variabel Intervening (Studi Kasus pada Perusahaan 
Manufaktur yang Terdaftar pada Bursa Efek Indonesia). Skripsi Sekolah Tinggi Ilmu Ekonomi Nobel Indonesia Makassar.

Santoso, Agus. 2017. Pengaruh Good Corporate Governance Terhadap Nilai Perusahaan dengan Kinerja Keuangan sebagai Variabel Intervening. Prosiding Seminar Nasional Jember.

Setiawan, Soni. 2019. Pengaruh Kinerja Lingkungan terhadap Kinerja Keuangan dengan Corporate Social Responsibility (CSR) sebagai Variabel Intervening. Skripsi Fakultas Ekonomi dan Bisnis Universitas Lampung.

Sudaryanto. 2011. Pengaruh Kinerja Lingkungan terhadap Kinerja Finansial Perusahaan dengan Corporate Social Responsibility (CSR) Disclosure sebagai Variabel Intervening. Skripsi Fakultas Ekonomi Universitas Diponegoro Semarang.

Sugiyono. 2013. Metodologi Penelitian Kuantitatif, Kualitatif dan $R \& D$. Bandung: ALFABETA.

Supriadi, Raesty Mugni dkk. 2018. Pengaruh Kinerja Lingkungan terhadap Kinerja Keuangan melalui Corporate Social Responsibility Disclosure sebagai Variabel Intervening. Jurnal Prodi Akuntansi, Fakultas Ekonomi dan Bisnis Universitas Islam Bandung.

Theresa, Holly. 2017. Konflik Antara Masyarakat Malinau dan Perusahaan Tambang Akibat Pencemaran Lingkungan. https://www.kompasiana.com/ollytheresa/59d1c22ede200d10343f94e2/akib at-jebolnya-tanggul-perusahaan-tambang-di-sungai-malinau. Diakses pada 06 Mei 2020.

Tim Penyusun, 2019. Pedoman Penulisan Skripsi. Jakarta: ITB Ahmad Dahlan Jakarta.

Widhiastuti, Ni Luh Putu, dkk. 2017. Pengaruh Kinerja Lingkungan pada Kinerja Keuangan dengan Corporate Social Responsibility (CSR) sebagai Variabel Intervening. E-Jurnal Ekonomi dan Bisnis Universitas Udayana.

www.idx.co.id 